Rowan University

Rowan Digital Works

Faculty Scholarship for the College of Science \& Mathematics

$11-1-2011$

\title{
Mindfulness predicts less texting while driving among young adults: Examining attention- and emotion-regulation motives as potential mediators.
}

\author{
Greg Feldman \\ Jeffrey M. Greeson \\ Rowan University, greeson@rowan.edu \\ Megan Renna \\ Kendra Robbins-Monteith
}

Follow this and additional works at: https://rdw.rowan.edu/csm_facpub

Part of the Health Psychology Commons

\section{Recommended Citation}

Feldman, G., Greeson, J., Renna, M., \& Robbins-Monteith, K. (2011). Mindfulness predicts less texting while driving among young adults: Examining attention- and emotion-regulation motives as potential mediators. Personality and individual differences, 51(7), 856-861.

This Article is brought to you for free and open access by the College of Science \& Mathematics at Rowan Digital Works. It has been accepted for inclusion in Faculty Scholarship for the College of Science \& Mathematics by an authorized administrator of Rowan Digital Works. 
Published in final edited form as:

Pers Individ Dif. 2011 November ; 51(7): 856-861. doi:10.1016/j.paid.2011.07.020.

\title{
Mindfulness predicts less texting while driving among young adults: Examining attention- and emotion-regulation motives as potential mediators
}

\author{
Greg Feldman, \\ Simmons College, Boston MA \\ Jeff Greeson, \\ Duke University Medical Center, Durham, NC \\ Megan Renna, and \\ Simmons College, Boston MA \\ Kendra Robbins-Monteith \\ Simmons College, Boston MA
}

\begin{abstract}
Many young adult drivers read and send text messages while driving despite clear safety risks. Understanding predictors of texting-while-driving may help to indentify relevant targets for interventions to reduce this dangerous behavior. The present study examined whether individual differences in mindfulness is associated with texting-while-driving in a sample of young-adult drivers. Using path analysis, we tested whether this relationship would be mediated by the degree to which individuals use text-messaging as a means of reducing unpleasant emotions (emotionregulation motives) and the degree to which individuals limit texting in order to focus on presentmoment experiences (attention-regulation motives). Individuals lower in mindfulness reported more frequent texting-while-driving and this relationship appeared to be mediated primarily by emotion-regulation motives. Results may help inform the development of mindfulness-based interventions to prevent texting-while-driving.
\end{abstract}

\section{Keywords}

mindfulness; emotion regulation; attention; text-messaging; driving

\section{Introduction}

Recent surveys find that one-fifth to one-third of young adult drivers report texting-whiledriving (Lenhart, Ling, Campbell, \& Purcell, 2010; Marist Poll, 2010), a practice with demonstrated public safety risks. Naturalistic studies of commercial vehicle operators reveal that texting-while-driving results in an over 20 fold increase in risk of safety critical events

\footnotetext{
(C) 2011 Elsevier Ltd. All rights reserved.

Correspondence concerning the article should be addressed to Greg Feldman, Simmons College, Department of Psychology, Park Science Center, 300 the Fenway, Boston, MA 02114. Phone: 617-521-2606; Fax: 617-521-3199; greg.feldman@ simmons.edu . Publisher's Disclaimer: This is a PDF file of an unedited manuscript that has been accepted for publication. As a service to our customers we are providing this early version of the manuscript. The manuscript will undergo copyediting, typesetting, and review of the resulting proof before it is published in its final citable form. Please note that during the production process errors may be discovered which could affect the content, and all legal disclaimers that apply to the journal pertain.
} 
such as crashes and near-accidents (Olson, Hanowski, Hickman, \& Bocanegra, 2009). Furthermore, a recent laboratory driving simulation study with young adult drivers (Drews, Yazdani, Godfrey, Cooper, \& Strayer, 2009) found that texting-while-driving produced a considerable increase in traffic accidents and slower reaction time to situations requiring use of brakes, relative to talking on a cell phone while driving. As a point of reference, a separate study found that talking on a phone while driving impaired safe driving more so than driving while intoxicated (Strayer, Drews \& Crouch, 2006).

Currently, 30 U.S. states have banned texting-while-driving (Governors Highway Safety Association, 2010). Unfortunately, such bans do not appear to reduce motor-vehicle accidents; paradoxically, there is some evidence that shows that bans are associated with increases in the overall number of accidents (Highway Loss Data Institute, 2010). Some have proposed addressing this public health issue clinically, for instance screening for texting-while-driving in primary care settings (Ship, 2010). Identifying potential psychological, behavioral, and environmental factors that predict texting-while-driving may help to guide the development of interventions that target relevant processes. However, there is scarce empirical data on psychological predictors of texting-while-driving ${ }^{1}$.

A relevant individual difference in understanding the phenomenon of texting-while-driving may be mindfulness, which has been defined as the tendency to intentionally attend to present-moment internal and external experiences with an attitude of openness and acceptance (Kabat-Zinn, 2005). Mindfulness has been studied both as a naturally-occurring individual difference as well as a state or quality that can be promoted through various lifestyle practices including mindfulness meditation (Brown, Ryan, \& Creswell, 2007).

Pioneering mindfulness teacher and researcher Jon Kabat-Zinn (2005) recently proposed that promoting mindfulness would help to lower individuals' harmful, over-reliance on mobile communication technology ${ }^{2}$. In addition to obvious dangers of mobile phone use while driving, he argues that communication technology may lead to more subtle psychological harm by distracting and estranging people from their immediate experience, including social relationships and internal physical cues. He also suggests that excessive use of communication technology may be driven by a desire to distract oneself from upsetting emotional states such as anxiety, loneliness, or boredom. In contrast, Kabat-Zinn suggests that individuals who are mindful in daily life would be expected to place a higher premium on being aware of their internal and external present-moment experiences and show greater openness to accepting rather than suppressing emotional states with high-tech distractions. These intriguing ideas have not been tested empirically but would appear to hold great promise in helping to understand the phenomenon of texting-while-driving.

Previous research using self-report, behavioral, and neurobiological measures has indicated that individuals low in trait mindfulness evidence difficulties with both emotion regulation (Arch \& Craske, 2010; Baer, Smith, Hopkins, Krietemeyer, \& Toney, 2006; Creswell, Way, Eisenberger, \& Lieberman, 2007; Feldman, Hayes, Kumar, Greeson, \& Laurenceau, 2007) and attention regulation (Schmertz, Anderson, \& Robins, 2009). Furthermore, personality traits characterized by difficulty in emotion regulation, such as neuroticism and impulsivity, are associated with greater frequency of texting (Butt \& Phillips, 2008; Ehrenberg, Juckes, White, \& Walsh, 2008) and use of mobile phones in dangerous and prohibited situations (Billieux, Van Der Linden, \& Rochat, 2008). As such, some people may use texting to regulate unpleasant emotional states, for example, to distract themselves from upsetting

${ }_{1}^{1}$ See Nemme \& White (2010) for a recent exception.

${ }^{2}$ Kabat-Zinn (2005) did not specifically address text-messaging, which was less prevalent at the time. Nonetheless, his observations about the potential psychological costs of excessive email and mobile phone use are clearly applicable to the issue at hand. 
feelings or to heightening stimulation and feelings of connection when bored or lonely. Texting to regulate emotions may be especially likely when people are engaged in the relatively automated and typically solitary activity of driving. Furthermore, deficits in attention regulation are observed among individuals who use text-messaging and other technology in a "multi-tasking" manner (Ophir, Nass, \& Wagner, 2009). Thus, people who would rather give their full attention to daily activities such as socializing or attending a lecture without the concurrent distraction of text-messages may also be less likely to divide their attention between texting and driving. However, no studies have yet examined whether natural variation in mindfulness as a dispositional quality is related to how frequently young adults send or read text messages while they are driving, and, if so, whether this relationship is partly explained by individual differences in emotion- and attention-regulation motives.

Thus, the goal of the present study was to test whether individual differences in self-reported levels of mindfulness predict texting-while-driving in a sample of young-adult drivers. We hypothesized that mindfulness would be inversely correlated with frequency of textingwhile-driving, and that this relationship would be mediated by two other individual difference variables: 1 ) the degree to which individuals use text-messaging as a means of reducing unpleasant emotions (emotion-regulation motives), and 2) the degree to which individuals limit texting in order to focus on present-moment experiences (attentionregulation motives). Three additional contextual variables likely associated with increased texting while driving were included in the model as covariates-frequency of driving, owning a mobile phone with a full keyboard, and subscribing to a mobile phone plan with flat-rate, unlimited texting - in the interest of reducing the likelihood of specification errors attributable to omitting relevant variables (Kline, 2010).

\section{Methods}

\section{Participants}

Participants were 231 undergraduate students attending a small private women's college in Massachusetts. As such all participants were female (Age: $\mathrm{M}=19.74, \mathrm{SD}=2.27$ ). In terms of ethnicity, $82.3 \%$ identified as Caucasian/White, $9.1 \%$ as Asian or Pacific Islander, 2.6\% as Black or African-American, 5.2\% circled two or more ethnicities or circled "other," and . $4 \%$ left this item blank. $94.8 \%$ identified as non-Hispanic, $4.3 \%$ identified as Hispanic, and . 9\% left this item blank. Students completed this survey in exchange for credit applied towards a psychology course in which they were enrolled. The study was approved by the relevant Institutional Review Board before data collection commenced. Participants completed written informed consent procedures before participating.

The sample used for the present study was a subset of participants from a larger study examining various aspects of mobile communication and social networking among college students. Participants in the larger study were excluded from the present analyses on texting while driving if they indicated that they do not own a mobile phone capable of sending text messages or if they reported not driving, not having a driver's license, or not having access to a car at any point during the year. Data were collected in the Fall of 2009 and Spring of 2010, prior to the introduction of legislation banning texting while driving in Massachusetts in Fall, 2010.

\section{Measures}

Mindfulness was assessed with the Cognitive and Affective Mindfulness Scale - Revised (CAMS-R; Feldman et al., 2007). The CAMS-R consists of 12 items assessing individual differences in capacity to focus attention on present moment experience, as well as awareness and acceptance of thoughts and feelings. Higher scores indicate greater 
mindfulness. Prior research has found that scores of the CAMS-R are correlated with other self-report measures of mindfulness and conceptually-related constructs and exhibit acceptable internal consistency in student and clinical samples (present study, $\alpha=.80$, CI: . 76 - .84) (Baer et al., 2006; Feldman et al., 2007; Greeson et al., in press; Schmertz et al., 2009). Furthermore, CAMS-R scores have been shown to be sensitive to change among individuals participating in clinical interventions that include training in mindfulness practice (Greeson et al., in press).

To assess frequency of texting while driving, participants were asked to rate how often they write and/or read text messages while driving using a 4 point scale $(1=$ Never, $2=$ Rarely, 3 $=$ Sometimes, 4 = Often). Emotion- and attention-regulation motives related to text messaging were assessed with items created for the present study in light of a lack of published measures of these constructs. Participants were asked to respond to items using the same 4 point scale described above. Three items assessed emotion-regulation motives: "When I am feeling upset, I send or read text messages to distract myself," "I send or read text messages to mentally 'check-out' from some situations," and "If I am bored or annoyed with the people I am with, I will text someone else" ( $\alpha=.68$, CI: .60 - .74). Another three items assessed attention-regulation motives: "I feel like I miss out on things around me when I am texting," "I dislike getting a text message because it interrupts what I am doing," and "I switch off my phone to avoid being distracted by incoming messages" $(\alpha=.53, \mathrm{CI}$ : . 41 - .62). To assess the three covariates, participants were asked to indicate 1) if their phone has a full keyboard for typing text messages, 2) if their cell phone plan included unlimited text messaging, and 3) their frequency of driving in terms of whether they drive during the full year or drive part of the year, for instance, when home from school during breaks. For analyses, covariates were dummy-coded such that $1=$ Yes and $0=$ No for the full-keyboard and unlimited plan variables. Year-round driving was coded as 1 and partial-year driving was coded as 0 .

\section{Analytic Plan}

Patterns of predicted relationships among study variables were tested using structural equation modeling (SEM; Kline, 2010). Path models were analyzed using Mplus version 6 (Muthén \& Muthén, Los Angeles, CA) using maximum likelihood estimation. All variables were screened for missing data and distributional assumptions prior to analysis. All continuous variables were relatively normally distributed (skewness and kurtosis <2).

Consistent with recommendations to test multiple a priori models of the data (Anderson \& Gerbing, 1988), two alternative path models were specified and compared for best fit. Both models tested the prediction that the effect of mindfulness on texting while driving would be mediated by emotion- and attention-regulation motives with year-round driving as a covariate. In Model A, having an unlimited texting plan and having a phone with a keypad were conceptualized as consumer behaviors informed by individual differences in emotionregulation motives; in other words, we predicted that individuals who tend to use texting to regulate emotions were more likely to select phones and texting payment plans that would increase the ease with which one could send text messages. Therefore, in Model A, these contextual variables were examined as partial mediators of the effect of texting to regulate emotions on texting while driving. In Model B, these variables were treated as independent covariates predicting texting while driving but unrelated to any other individual difference variables. Thus, in Model B, the paths from emotion regulation motives to these two variables were fixed to 0 .

Chi-squared difference tests were used to compare the relative fit of nested models (Kline, 2010). Parameter estimates - including path coefficients for direct, indirect, and total associations between model variables - and $\mathrm{R}^{2}$ values were tested for statistical significance 
( $\mathrm{z}=1.96, \alpha=.05$, two-tailed). The following criteria were used as indices of good model fit: (1) a non-significant $\chi^{2}$; (2) comparative fit index (CFI) $>.95$; (3) root mean square error of approximation (RMSEA) <.06; and (4) standardized root mean squared residual (SRMR) <. 08 (Hu \& Bentler, 1999; Kline, 2010).

\section{Results \\ Descriptive statistics}

Descriptive statistics and correlation matrix for all variables are presented in Table 1. The mean for the CAMS-R is consistent with prior samples of female college students (e.g., Feldman et al., 2007). Of note, $29.9 \%$ of participants reported "never" texting while driving whereas $39.0 \%$ report doing so "rarely," 27.3\% "sometimes," and 3.9\% "often." 3

\section{Path models}

Model A demonstrated good fit to the data on all criteria $\left(\chi^{2}=14.30, d f=10, p=.16\right.$, CFI $=.95$, RMSEA $=.04(\mathrm{CI}: .00-.09)$, SRMR $=.04)$. In contrast, Model $\mathrm{B}$ did not fit the data well, suggesting that omitting the relationships between texting to regulate emotions and having an unlimited texting plan and a phone with a keypad led to poor fit $\left(\chi^{2}=29.08, d f=\right.$ $12, p=.0038, \mathrm{CFI}=.80$, RMSEA $=.08$ (C.I. $=.04-.12$ ), SRMR $=.07 ; \Delta \chi^{2}=14.78, d f=2$, $p<.001)$. Given the superiority of Model A in terms of goodness of fit, it will be the focus of the remaining results section (See Figure 1).

Consistent with univariate analyses, a significant association was found between greater mindfulness and less texting while driving (total effect: $\beta=-.164, p=.008$ ). This association was primarily explained by a significant partial mediating effect of texting to regulate emotions (indirect effect: $\beta=-.053, p=.011$ ). As predicted, possessing a phone with a full keypad and having an unlimited texting plan partly accounted for the relationship between texting to regulate emotions and texting while driving. The direct effect of emotionregulation motives on texting while driving remained significant above and beyond these two pathways $(\beta=.27, p<.001)$; however, the indirect paths via having an unlimited texting plan $(\beta=.03, p=.06)$ and having a keyboard $(\beta=.03, p=.07)$ both approached statistical significance, suggesting partial mediation. The direct effect of mindfulness and the indirect effect of attention-regulation were not statistically significant when accounting for yearround driving and all other variables simultaneously.

Prior to running the full hypothesized path model, a preliminary model was run to establish the effect of mindfulness on texting while driving prior to adding attention- and emotionregulation motives to the model. For this analysis, the three contextual variables were also entered as covariates. In these analyses, the path from mindfulness to texting while driving $(\beta=-.15, \mathrm{p}=.02)$, which suggests that there was a significant direct effect on this dependent variable above and beyond the contextual covariates. However, as noted above, once the two mediators were entered into the model the effect of mindfulness on texting while driving fell to non-significance $(\beta=-.08, \mathrm{p}=.19)$

To further examine whether these variables fully mediated the effect of mindfulness on texting while driving, a nested model was tested in which the direct path between mindfulness and texting while driving was constrained to 0 . This more parsimonious model provided an equivalent, acceptable fit to the data $\left[\chi^{2}=16.03, \mathrm{df}=11, \mathrm{p}=.14 ; \mathrm{CFI}=.94\right.$; RMSEA $=0.05,90 \%$ Percent C.I. $=0.00-0.09 ;$ SRMR $\left.=0.04 ; \Delta \chi^{2}=1.73, \Delta \mathrm{df}=1, n s\right)$.

\footnotetext{
${ }^{3}$ These rates are somewhat higher than those reported in other recent surveys of young adult drivers (Lenhart et al., 2010; Marist Poll, 2010); however, this may be due in part to variability in wording and response options across surveys.
} 
These results are consistent with the hypothesis that the association of mindfulness and texting while driving is fully mediated by emotion-regulation motives.

The final model (Figure A) with 6 predictor variables accounted for $22 \%$ of the variance in texting while driving $(\mathrm{p}<.001)$. In contrast, relatively less variance was explained in the four mediating variables (Emotion-regulation motives, $\mathrm{R}^{2}=.04, \mathrm{p}=.12$; Attentionregulation motives, $\mathrm{R}^{2}=.05, \mathrm{p}=.09$; Unlimited texting plan, $\mathrm{R}^{2}=.03, \mathrm{p}=.15$; Keyboard, $\mathrm{R}^{2}=.03, \mathrm{p}=.18$ ). Following the Cohen (1988) guidelines for interpreting $\mathrm{R}^{2}$, this suggests a medium effect size for the combination of variables predicting texting while driving and a small effect for the four mediators.

\section{Discussion}

The present study tested a theoretically-grounded model examining individual difference and contextual predictors of texting while driving in a sample of young adult drivers. The main findings supported the hypothesis that individuals lower in mindfulness tended to report more frequent texting while driving. In addition, findings suggested that this relationship was explained by individual differences in emotion-regulation motives (i.e., texting to ameliorate negative emotional states) and attention-regulation motives (i.e., limiting texting to allow greater attention to day-to-day experience). Path analysis more strongly supported emotion-regulation motives as a mediator of how frequently young adults text message while they drive. These resulting linking individual differences in dispositional qualities with texting behavior is important because texting-while-driving is associated with an increased the risk of motor vehicle accidents. Nonetheless, many young adults engage in this behavior. Nearly one-third of the present sample of young adult drivers reported sending or reading texts while driving with some regularity. Understanding predictors and correlates of texting-while-driving may help to indentify relevant targets for interventions to reduce this dangerous behavior.

The current results are consistent with past research that showed how individuals low in mindfulness are more likely to have difficulty regulating emotions and may be more likely to employ maladaptive strategies to manage emotions (Arch \& Craske, 2010; Baer et al., 2006; Creswell et al., 2007; Feldman et al., 2007). The present study extended prior work by being the first to demonstrate a link between mindf ulness and the use of texting as an emotion regulation strategy. It is also the first to find that emotion-regulation motives for texting are linked to texting-while-driving and that emotion regulation motives may influence consumer behaviors that would facilitate more frequent texting.

Attention-regulation motives were associated with mindfulness and with texting-whiledriving in a univariate analysis but not the multivariate path analysis. This effect may have been diminished by the nature of the measure created for this study to capture this construct. In particular, the score for this scale exhibited relatively low internal consistency, which may be attributable in part to the scales' brevity as well as efforts to cover a variety of facets of these constructs and avoid redundant language in the items (see John \& Benet-Martinez, 2000). On the one hand, measures with low alpha values may be acceptable in the early stages of research into a new psychological phenomenon (Nunnally \& Bernstein, 1994), as is the case with this study. Nonetheless, it is important to note that associations between attention-regulation motives and other variables may be attenuated in the present study.

Results suggest that the six predictor variables in the present model account for a little over one-fifth of the variance in texting-while-driving (a medium effect size); however, the effects of the individual predictors on each mediator tended to exhibit effect sizes in the small range. This suggests that there are likely a host of other relevant predictor variables 
that future research should consider. For instance, variables related to the theory of planned behavior (e.g., attitudes about texting-while-driving, perceived social norms) prospectively predicted nearly $30 \%$ of the variance in texting-while-driving (Nemme \& White, 2010). Thus, future research integrating both mindfulness and the theory of planned behavior holds prom ise for understanding psychological factors contributing to texting-while-driving.

The present study has several limitations that should be noted. First, the use of crosssectional data limits the ability to make inferences about temporal relationships between variables. Second, the use of self-report data to assess texting-while-driving may have compromised accuracy due to recall errors and social desirability. This latter issue may have been attenuated somewhat in the present study given that texting-while-driving had not been outlawed at the time of data collection. Future studies would benefit from more objective measures of texting-while-driving, for instance the use of mobile phone records or automated event recorders. Third, the sample used in the present study (female college students) offers both strengths and limitations. On the one hand, this sample could be conceptualized as being at-risk for texting-while-driving given that younger drivers are more likely than more experienced drivers to text and drive (e.g., Marist, 2010). The use of an allfemale sample may limit generalizability in light of potential gender differences in the experience and regulation of emotions; however, gender differences in texting-while-driving have not been observed in other samples of young drivers (e.g., Lenhart et al., 2010; Marist Poll, 2010; Nemme \& White, 2010). In sum, results may not generalize to drivers who are male, older, less educated, or more frequent drivers than this sample. Nonetheless, results may help illuminate relevant factors for drivers in an at-risk age group.

Although the results of the present study should be regarded as preliminary in light of these limitations, they offer potentially helpful clues to inform targets of intervention to decrease the public health risks posed by texting-while-driving. First, it is informative to note that all three contextual variables examined in the present model (frequency of driving, owning a mobile phone with a full keypad, and a mobile phone plan with unlimited texting) were independent, significant predictors of texting-while-driving. Future experimental research could examine whether manipulating one (or all) of these variables would result in a reduction of texting-while-driving. Indeed, such technology-based environmental modifications have been proposed to curb texting-while-driving (Johnson, 2009). However, in the present study, emotion regulation motives remained a significant independent predictor of texting-while-driving above and beyond these three contextual variables, raising the prospect that modifying these contextual variables would still leave a relevant risk factor unaddressed.

Mindfulness-based interventions may offer some promise in terms of addressing emotionregulation as a potential risk factor. For instance, mindfulness-based interventions have been shown to successfully reduce other risky and self-destructive behaviors that may serve an emotion-regulating function, including substance abuse (Bowen \& Marlatt, 2009), bingeeating (Kristeller, Baer, \& Quillian-Wolever, 2006), and non-suicidal self-injury (Neacsiu, Rizvi, \& Linehan, 2010). Furthermore, laboratory studies of individuals without prior meditation experience suggest that even brief practice of mindfulness exercises may help to promote reduced emotional reactivity (Arch \& Craske, 2006), more rapid recovery from a negative mood (Broderick, 2005), and less distress in response to repetitive thoughts (Feldman, Greeson, \& Senville, 2010). As such, it is possible that brief mindfulness exercises practiced before or while driving may help to alleviate potential affective and cognitive factors that may serve as triggers for texting-while-driving. Further research is needed to examine the feasibility, desirability, and—ultimately—efficacy of such interventions. 
In conclusion, the present study provides initial evidence that individual differences in mindfulness are associated with a reduced likelihood of texting-while-driving. The study also suggests that individuals low in mindfulness may engage in texting-while-driving as a means to regulate negative emotions. These novel findings suggest that the constructs of mindfulness and emotion regulation deserve further attention from researchers, policy makers, and clinicians interested in understanding and preventing texting-while-driving.

\section{Acknowledgments}

The second author was supported by grant K99 AT004945 from the National Center for Complementary \& Alternative Medicine (NCCAM) at the National Institutes of Health (NIH). We wish to thank the students in the Fall 2009 PSY 304 seminar at Simmons College for their help with data collection.

\section{References}

Anderson JC, Gerbing DW. Structural equation modeling in practice: A review and recommended two-step approach. Psychological Bulletin. 1988; 103:411-423. doi:10.1037/0033-2909.103.3.411.

Arch JJ, Craske MG. Mechanisms of mindfulness: Emotion regulation following a focused breathing induction. Behaviour Research and Therapy. 2006; 44:1849-1858. doi: 10.1016/j.brat.2005.12.007. [PubMed: 16460668]

Arch JJ, Craske MG. Laboratory stressors in clinically anxious and non-anxious individuals: The moderating role of mindfulness. Behaviour Research and Therapy. 2010; 48:495-505. doi: 10.1016/ j.brat.2010.02.005. [PubMed: 20303471]

Baer RA, Smith GT, Hopkins J, Krietemeyer J, Toney L. Using self-report assessment methods to explore facets of mindfulness. Assessment. 2006; 13:27-45. doi:10.1177/1073191105283504. [PubMed: 16443717]

Billieux J, Van Der Linden M, Rochat L. The role of impulsivity in actual and problematic use of the mobile phone. Applied Cognitive Psychology. 2008; 22:1195-1210. doi: 10.1002/acp.1429.

Bowen S, Marlatt A. Surfing the urge: Brief mindfulness-based intervention for college student smokers. Psychology of Addictive Behaviors. 2009; 23:666-671. doi: 10.1037/a0017127. [PubMed: 20025372]

Broderick PC. Mindfulness and coping with dysphoric mood: Contrasts with rumination and distraction. Cognitive Therapy and Research. 2005; 29:501-510. doi:10.1007/s10608-005-3888-0.

Brown K, Ryan RM, Creswell J. Mindfulness: Theoretical foundations and evidence for its salutary effects. Psychological Inquiry. 2007; 18:211-237.

Butt S, Phillips JG. Personality and self-reported mobile phone use. Computers in Human Behavior. 2008; 24:246-360. doi:10.1016/j.chb.2007.01.019.

Cohen, J. Statistical power analysis for the behavioral sciences. 2nd ed. Academic Press; New York: 1988.

Creswell J, Way BM, Eisenberger NI, Lieberman MD. Neural correlates of dispositional mindfulness during affect labeling. Psychosomatic Medicine. 2007; 69:560-565. doi:10.1097/PSY. 0b013e3180f6171f. [PubMed: 17634566]

Drews FA, Yazdani H, Godfrey CN, Cooper JM, Strayer DL. Text messaging during simulated driving. Human Factors. 2009; 51:762-770. doi:10.1177/0018720809353319. [PubMed: 20196300]

Ehrenberg A, Juckes S, White KM, Walsh SP. Personality and self-esteem as predictors of young people's technology use. CyberPsychology and Behavior. 2008; 11:739-741. doi:10.1089/cpb. 2008.0030. [PubMed: 18991531]

Feldman G, Greeson J, Senville J. Differential effects of mindful breathing, progressive muscle relaxation, and loving-kindness meditation on decentering and negative reactions to repetitive thoughts. Behaviour Research and Therapy. 2010; 10:1002-1011. doi:10.1016/j.brat.2010.06.006. [PubMed: 20633873]

Feldman G, Hayes A, Kumar S, Greeson J, Laurenceau JP. Mindfulness and emotion regulation: The development and initial validation of the Cognitive and Affective Mindfulness Scale-Revised 
(CAMS-R). Journal of Psychopathology and Behavioral Assessment. 2007; 29:177-190. doi: 10.1007/s10862-006-9035-8.

Greeson JM, Webber DM, Smoski MJ, Brantley JG, Ekblad AG, Suarez EC, Wolever RQ. Changes in spirituality partly explain health-related quality of life outcomes after Mindfulness-Based Stress Reduction. Journal of Behavioral Medicine. (in press). doi: 10.1007/s10865-011-9332-x.

$\mathrm{Hu}$ LM, Bentler PM. Cutoff criteria for fit indexes in covariance structure analysis: conventional criteria versus new alternatives. Structural Equation Modeling. 1999; 6:61-55.

John, OP.; Benet-Martínez, V. Measurement: Reliability, construct validation, and scale construction. In: Reis, HT.; Judd, CM.; T., H., editors. Handbook of research methods in social and personality psychology. Cambridge University Press; New York, NY: 2000. p. 339-369.

Johnson BD. Cell phone and choice architecture. Injury Prevention. 2009; 15:289-290. [PubMed: 19805594]

Kabat-Zinn, J. Coming to our senses: Healing ourselves and the world through mindfulness. Hyperion; New York, NY: 2005.

Kline, RB. Principles and practice of structural equation modeling. Guilford; New York, NY: 2010.

Kristeller, JL.; Baer, RA.; Quillian-Wolever, R. Mindfulness-based approaches to eating disorders. In: Baer, RA., editor. Mindfulness-based treatment approaches: Clinician's guide to evidence base and applications. Elsevier; San Diego, CA, US: 2006. p. 75-91.

Neacsiu AD, Rizvi SL, Linehan MM. Dialectical behavior therapy skills use as a mediator and outcome of treatment for borderline personality disorder. Behaviour Research and Therapy. 2010; 48:432-439. doi:10.1016/j.brat.2010.05.017.

Nemme HE, White KM. Texting-while-driving: Psychosocial influences on young people's texting intentions and behaviour. Accident Analysis and Prevention. 2010; 42:1257-1265. doi:10.1016/ j.aap.2010.01.019. [PubMed: 20441840]

Nunnally, J.; Bernstein, I. Psychometric theory. McGraw Hill; New York, NY: 1994.

Ophir E, Nass C, Wagner AD. Cognitive control in media multitaskers. Proceedings of the National Academy of Sciences of the United States of America. 2009; 106:15583-15587. doi:10.1073/pnas. 0903620106. [PubMed: 19706386]

Schmertz K, Anderson PL, Robins DL. The relation between self-report mindfulness and performance on tasks of sustained attention. Journal of Psychopathology and Behavioral Assessment. 2009; 31:60-66. doi:10.1007/s10862-008-9086-0.

Ship AN. The most primary of care-Talking about driving and distraction. The New England Journal of Medicine. 2010; 362(23):2145-2147. [PubMed: 20558364]

Strayer DL, Drews FA, Crouch DJ. A comparison of the cell phone driver and the drunk driver. Human Factors. 2006; 48:381-391. [PubMed: 16884056]

\section{Web references}

Governors Highway Safety Association. Cell phone and texting laws. 2010. Retrieved from http://www.ghsa.org/html/stateinfo/laws/cellphone_laws.html

Highway Loss Data Institute. Laws banning cellphone use while driving fail to reduce crashes, new insurance data indicate. 2010. Retrieved from http://www.iihs.org/news/rss/pr012910.html

Lenhart, A.; Ling, R.; Campbell, S.; Purcell, K. Teens and mobile phones. 2010. Retrieved from http://pewinternet.org/Reports/2010/Teens-and-Mobile-Phones.aspx

Marist, Poll. 2010. Retrieved from: http://maristpoll.marist.edu/wp-content/misc/usapolls/us091007/Texting\%20While\%20Driving/ Frequency\%20of\%20Texting\%20While\%20Driving.htm

Olson, RL.; Hanowski, RJ.; Hickman, JS.; Bocanegra, J. Driver distraction in commercial vehicle operations. U.S. Department of Transportation, Federal Motor Carrier Safety Administration; Washington, DC: 2009. Report no. FMCSA-RRR-09-042)Retrieved from www.fmcsa.dot.gov/facts-research/research-technology/report/FMCSA-RRR-09-042.pdf 


\section{Highlights}

- Many young adult drivers read and send text messages while driving despite clear safety risks.

- In this study, individuals lower in mindfulness reported more frequent texting while driving.

- The use of text-messaging to reduce unpleasant emotions primarily mediated this relationship.

- This study is the first to show a link between mindfulness and texting while driving.

- Results may help inform the development of interventions to prevent texting while driving. 


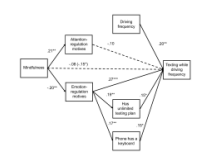

Figure 1.

Results of path analysis testing direct and indirect effects of mindfulness on texting-whiledriving. Path coefficients are standardized regression $(\beta)$ weights. Solid arrows represent statistically significant associations $(p<.05)$. Dashed arrows represent non-significant $(n s)$ relationships $(p>.05)$. In the path from Mindfulness to Texting-While-Driving Frequency, the value in parentheses reflects the association of these two variables prior to adding the two mediators (attention- and emotion-regulation motives), controlling for the three remaining variables in the model.

$* \mathrm{p}<.05, * * \mathrm{p}<.01, * * * \mathrm{p}<.001$. 


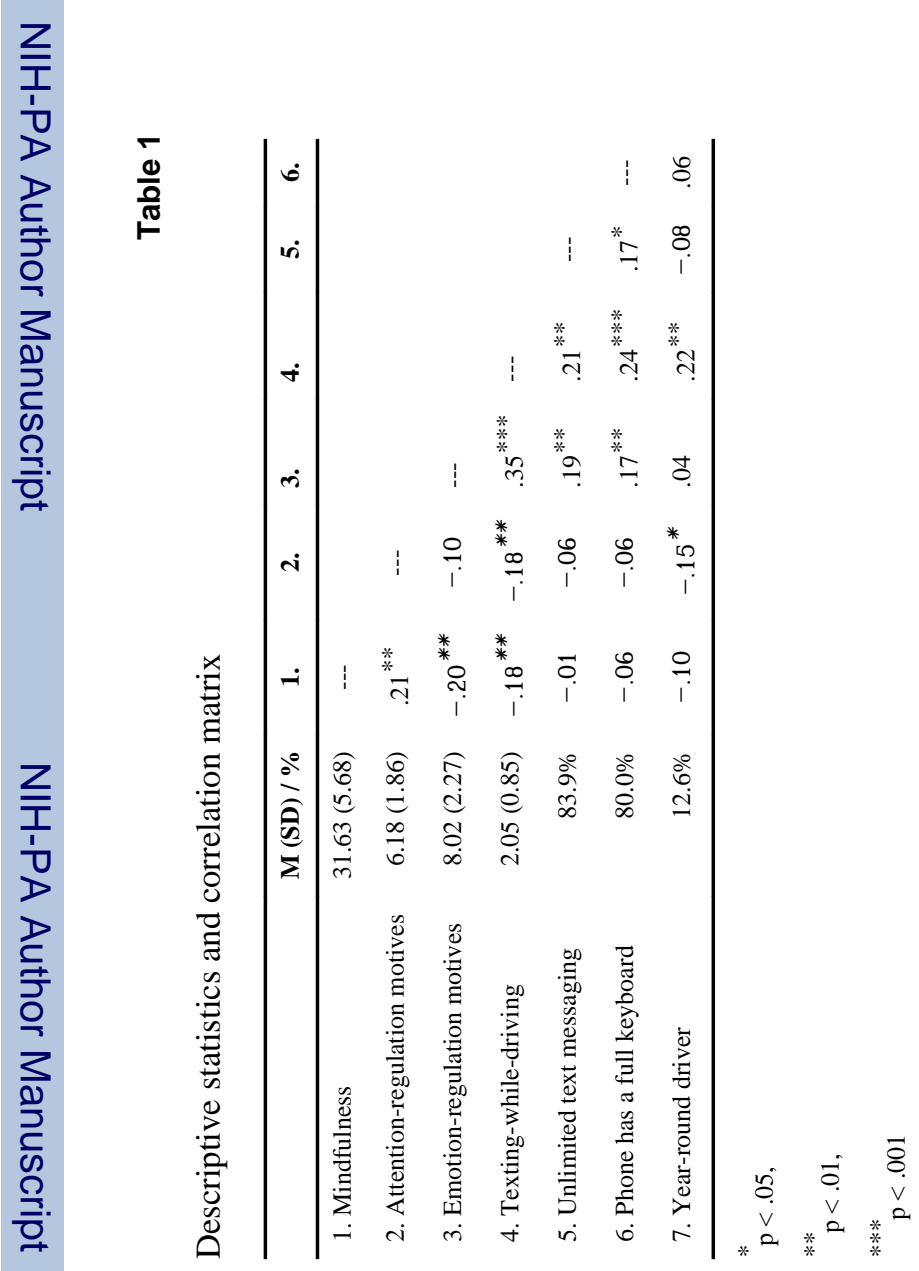

Pers Individ Dif. Author manuscript; available in PMC 2012 November 1. 